Thorax (1961), 16, 176.

\title{
PNEUMOCONIOSIS DUE TO FULLER'S EARTH
}

BY

\author{
A. SAKULA \\ From the Redhill Chest Clinic, Surrey
}

(RECEIVED FOR PUBLICATION OCTOBER 6, 1960)

Fuller's earth is one of the less common causes of pneumoconiosis, and only two earlier necropsy reports incriminating it have been found in the literature (Campbell and Gloyne, 1942 ; Tonning, 1949). Investigation of workers using fuller's earth at Nutfield, Surrey, found some patients with bronchitis possibly associated with the occupation, but in only two of these were there the distinctive radiological changes of a pneumoconiosis, and one of them came to necropsy. These two patients, who were exposed for 42 and 35 years respectively, are reported here.

\section{Case Reports}

CASE 1.-A. B., born in 1888, had worked with fuller's earth from 1906 to 1948. For the first 21 years he was a gas-engine driver, working in an atmosphere which contained much fuller's earth dust, some of which may have included anthracite. He then worked in the kilns and milling department, both very dusty at that time. He first attended the chest clinic in 1948, because of recurrent bronchitis and increasing dyspnoea during the previous two years.

On examination, his general condition was fairly good; there was no finger clubbing, there were no added sounds on auscultation, but chest expansion was poor. Chest radiographs showed fine to medium miliary mottling of both lungs, more marked in the midzones (Fig. 1). Sputum examinations were negative for $M$. tuberculosis. $\mathrm{He}$ was awarded compensation for pneumoconiosis, and over the years we found that his pulmonary function slowly deteriorated. In December, 1955, he had a cerebral thrombosis, leaving him with a left hemiplegia. In 1958 he died, but a necropsy was not performed.

CASE 2.-A. P. was born in 1895 . He worked with fuller's earth from 1922 to 1957 , and for 28 years he was milling. In 1955 his abnormal film was found by mass radiography, and so he was referred to the chest clinic. He complained of chronic cough and sputum with increasing dyspnoea, but his general condition was quite good, and examination of the chest revealed little abnormality. A chest radiograph showed fine miliary mottling throughout both lungs. Repeated sputum cultures were negative for $M$. tuberculosis. He was awarded compensation for pneumoconiosis, and remained under observation. In 1956 he developed anginal symptoms, and in the next year right-sided cardiac failure developed. This was controlled, but in 1960 the picture of cor pulmonale became more pronounced, and in March, 1960, he collapsed and died.

Necropsy.-The lungs were emphysematous and congested, and the cut surfaces showed throughout very small (1-2 $\mathrm{mm}$.), round, firm black nodules, mainly perivascular, especially in the upper lobes. These nodules stood out from the surface, but were not hard like silicotic nodules, and there was no obvious fibrosis. There were pleural adhesions over the right upper lobe, but no subpleural nodules. There was an acute suppurative bronchitis, but no evidence of pulmonary tuberculosis.

The right ventricle was dilated and hypertrophied. There was no valvular disease. The coronary arteries showed moderate atheroma. The kidneys were congested and the surfaces smooth. The liver showed

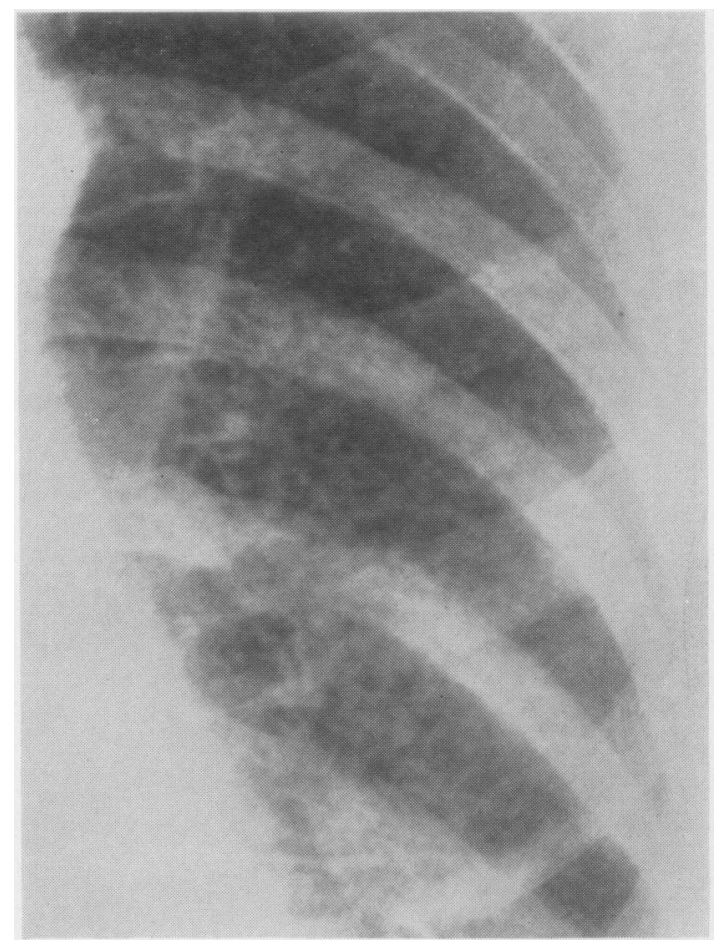

Fig. 1.-Case 1: Detail from left midzone, showing the miliary mottling. 


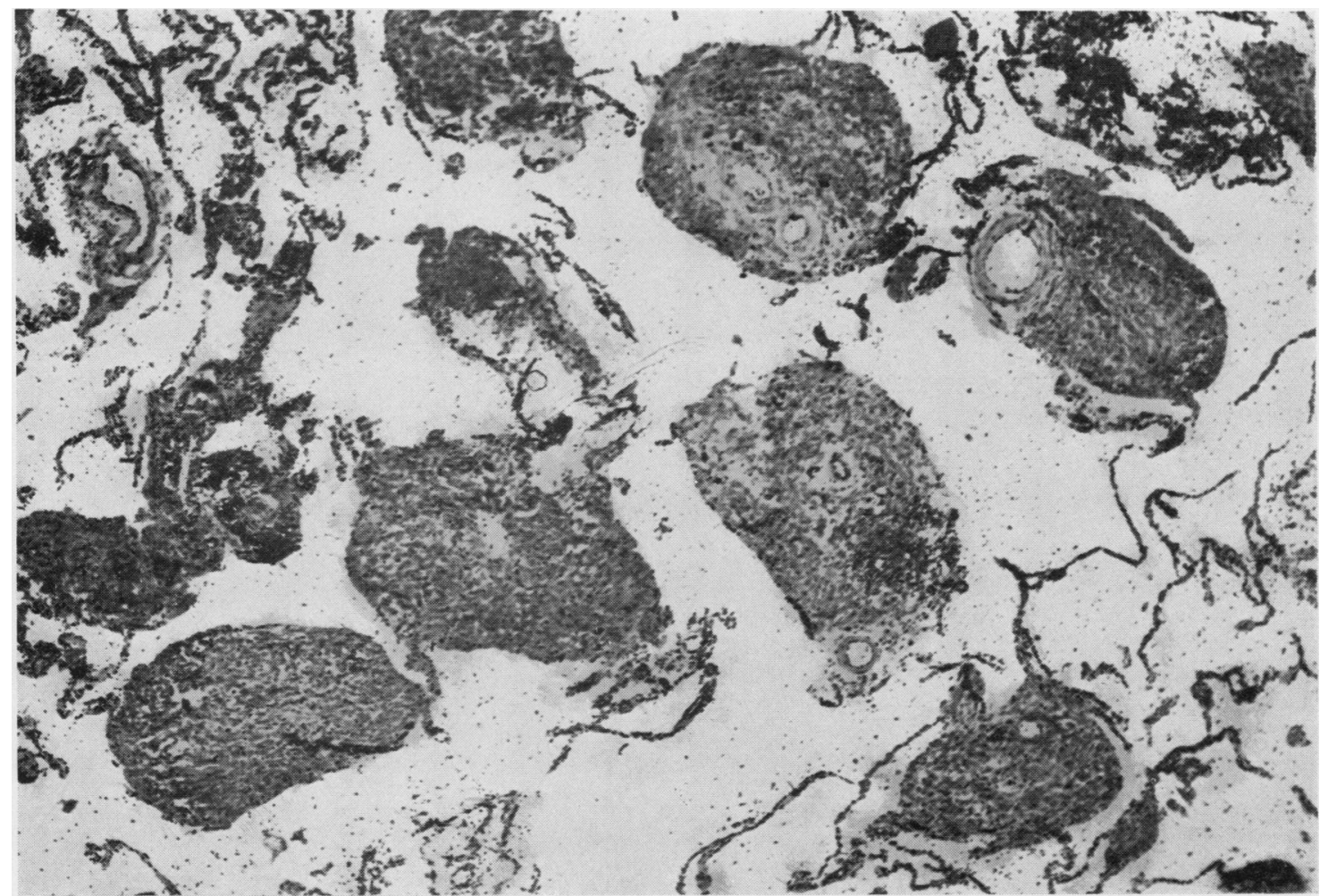

Fig. 2.-Pneumoconiosis due to fuller's earth. Section of lung (haematoxylin and cosin) from Case 2. Nodules were seen to be perivascular, and consisted essentially of masses of brown pigment in macrophages. Emphysema $(\times 50)$.

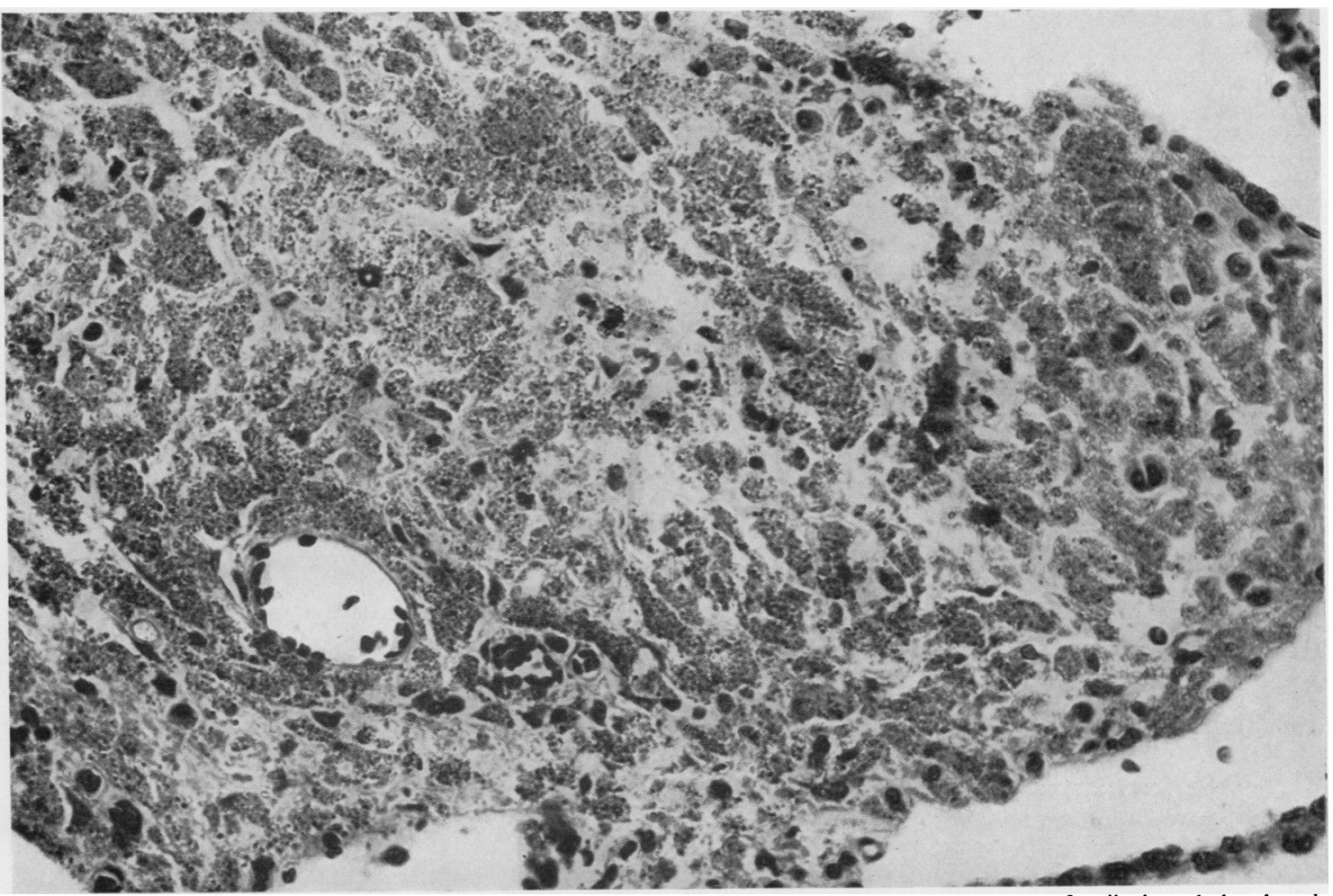

Fia. 3.-Higher magnification of a lung nodule.

Macrophages full of pigment. Several small slightly refractile irregularly shaped bodies $\{\times 350)$ 


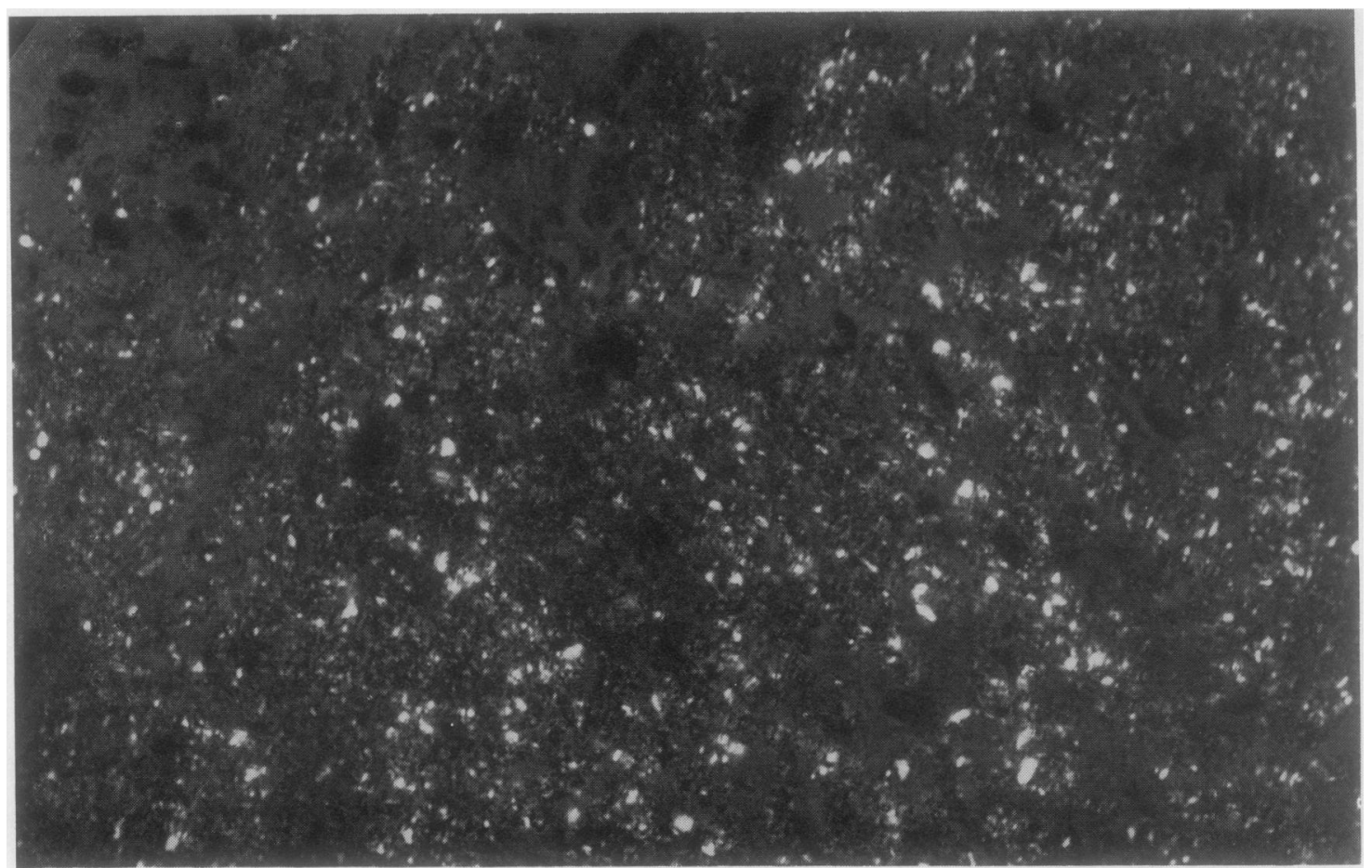

FIG. 4.-Under polarized light, numerous minute birefringent particles scattered throughout nodule. Larger, irregularly shaped bodies not birefringent $(\times 400)$.

recent chronic passive congestion. The spleen was slightly enlarged and congested. The adrenals appeared to be normal. The thyroid looked normal. The brain showed some congestion.

Histology of Lung.-The nodules, which were mainly perivascular and along the interlobular septa, were seen to consist of masses of brownish pigment in macrophages (Fig. 2). This pigment did not stain with ordinary aniline dyes, and the Prussian blue reaction was negative. A loose network of fine reticulin fibres was found by reticulin staining throughout each nodule, in which there were one or more slightly refractile, irregularly shaped bodies approximately $15 \mu$ in length and probably crystalline (Fig. 3). Under polarized light, these bodies were not birefringent and possibly they represent some mineral particles other than montmorillonite present in fuller's earth dust. In addition, numerous minute birefringent particles were seen scattered throughout each nodule (Fig. 4). The rest of the lung showed emphysema and patchy non-specific bronchopneumonia.

\section{Diffraction Studies}

$X$-ray diffraction studies of a portion of lung tissue after complete oxidation with hydrogen peroxide produced a pattern showing several diffraction lines characteristic of montmorillonite, as well as one line corresponding to feldspar, a crystalline silicate material.
Electron diffraction studies of an unstained microtome section produced a pattern corresponding to montmorillonite, and excluded the other triple layer minerals kaolinite, illite, and mica.

With both these methods, no quantitative conclusions could be drawn as to the concentration of montmorillonite in the lung.

\section{COMPosition of Fuller's EARTH}

Fuller's earth is an adsorbent clay mineral, consisting essentially of calcium montmorillonite. Montmorillonite is an aluminium silicate of approximate formula $(\mathrm{Al}, \mathrm{Fe}, \mathrm{Mg})_{4} \mathrm{Si}_{8} \mathrm{O}_{20}(\mathrm{OH})_{4}$, in which the relative amounts of $\mathrm{Al}, \mathrm{Fe}$, and $\mathrm{Mg}$ are not fixed. It should be distinguished from sodium montmorillonite, often known as bentonite. There are deposits of montmorillonite in various parts of the world, especially in the U.S.A. and Germany, but in Britain it is concentrated into a relatively small number of deposits, the chief centres being at Nutfield, near Redhill, Surrey, in Somerset around Bath, and also in Bedfordshire and Kent. It is usually found among Jurassic and Cretaceous rocks, and probably originated by decomposition of primary rocks in water or from volcanic ash. It is obtained by intensive open-cast quarrying, and the clay is processed by drying and grinding to produce "natural" fuller's earth. 
"Activated" fuller's earth is obtained by chemical treatment. In addition to calcium montmorillonite, fuller's earth contains small amounts of natural impurities, namely, calcite, feldspar, zinc blend, apatite, limonite, and rarely quartz.

The earth when quarried is a grey, soap-like substance and is basically crystalline. Electron microscope studies have shown these crystals to be very small, approximately $0.4 \times 0.004$ microns. Despite this basic crystalline structure the powder behaves as though it were amorphous. Its high adsorptive, base exchange, and bonding properties give it its importance as an industrial substance.

\section{USES}

The ancient Greeks and Romans knew fuller's earth as a bleach and as a primitive soap. By the Middle Ages it was mainly used for scouring raw wool, for removing surplus dye from cloth, and finishing and thickening ("fulling") the woollen cloth. It was at one time such a mainstay of the British woollen industry that smuggling it out of the country was a serious offence. It has also been used as a base for cosmetics, powders (e.g., baby, napkin, toilet powder), etc., but in modern times its main uses are in industrial processes, such as refining lubricating oils and edible and technical oils. It is also used for bonding foundry moulding sand and for oil-well drilling.

\section{Discussion}

For many years, exposure to fuller's earth had been regarded as harmless, but in 1938, at the Silicosis Conference of the International Labour Office of the League of Nations held in Geneva, Middleton drew attention for the first time to the effect of the dust on the human lung (Middleton, 1940). He had chest radiographs of five men working for four, five, 19,35 , and 39 years respectively at the fuller's earth works at Nutfield, Surrey. The last two showed nodulation, with a linear arrangement. Afterwards, McNally and Trostler (1941) examined 49 men working at the fuller's earth plant at Olmstead, Illinois, U.S.A., and found a very variable reaction of the lung; usually the bronchial markings were increased, but in some cases there were mottled areas, especially in the upper lobes. They did not carry out any necropsies. The first published necropsy report was by Campbell and Gloyne (1942), who described the histological changes in the lungs of a fuller's earth worker who died at the age of 56, after 38 years' exposure to the dust. There was a soft patchy pneumoconiosis without massive fibrosis quite unlike silicosis. The second necropsy case was reported by Tonning (1949) from Canada, where a man aged 79 died after treatment for carcinoma of the lip. He had worked for 15 years with fuller's earth at Nutfield, Surrey, some 50 years previously before emigrating to Canada, and at necropsy the lungs showed a histological pattern almost identical with that described in this paper. The only other cases have come from Germany reported by Gattner (1955), who examined nine workers, of whom two showed a definite miliary radiological pattern, after 10 and 14 years' exposure respectively, but neither of these had any symptoms. There were no necropsies.

The histological changes in the lungs of Case 2 described here were similar to those described by Campbell and Gloyne (1942) and by Tonning (1949). There was a reticular type of fibrosis, but no whorls of acellular collagen as seen in classical silicosis. There were no subpleural nodules, nor evidence of massive fibrosis, nor of any complicating tuberculosis. The dust particles did not stain with ordinary dyes, but examination under polarized light showed the particles to be birefringent and scattered throughout the nodules. $X$-ray and electron diffraction studies confirmed the presence of montmorillonite in the lung tissue.

Fuller's earth is undoubtedly capable of damaging the human lung but less so than silica. Very long exposure and a high concentration of dust are necessary for this to happen. The radiological pattern seen is not due merely to shadows cast by dust accumulation, but does, in fact, reflect the biological reaction of the lung to the dust. The case described by Tonning well illustrates the persistence after very many years of the pulmonary changes following inhalation of the dust, without progression of the dust reticulation to silicotic fibrosis.

\section{SUMMARY}

Two cases of fuller's earth pneumoconiosis are described and illustrated. One of these came to necropsy and histologically the lungs showed a reticular fibrosis unlike silicosis. Dust particles were present in the lungs, and were demonstrated by $x$-ray and electron diffraction techniques to be identical with natural montmorillonite.

Fuller's earth dust is injurious to the human lung if the exposure is sufficiently concentrated or prolonged.

I should like to thank Dr. T. N. Gledhill for his report on the lung histology, and the research laboratories of the Fuller's Earth Union for carrying out the $x$-ray and electron diffraction studies.

\section{REFERENCES}

Campbell, A. H., and Gloyne, S. R. (1942). J. Path. Bact., 54, 75. Gattner, H. (1955). Arch. Gewerbepath. Gewerbehyg., 13, 508. McNally, W. D., and Trostler, I. S. (1941). J. industr. Hyg., 23, 118. Middleton, E. L. (1940). In Int. Lab. Off. Stud. Rpts. ser. F. Silicosis: Proc. int. Conf., Geneva, 1938, No. 17, pp. 25 and 134. Tonning, H. O. (1949). J. industr. Hyg., 31, 41. 